\title{
Social security or insecurity? The experience of welfare participation by financially vulnerable households in the Netherlands
}

\author{
Olaf Simonse $^{1,2}$ (1) | Gabry Vanderveen ${ }^{3}$ (i) | Lotte F. van Dillen ${ }^{1}$ (i) | \\ Wilco W. van Dijk ${ }^{1}$ (i) | Eric van Dijk ${ }^{1}$ (i)
}

${ }^{1}$ Faculty of Social and Behavioural Sciences, Leiden University, Knowledge Center Psychology and Economic Behavior, Leiden, The Netherlands

${ }^{2}$ Ministry of Finance, The Hague, The Netherlands

${ }^{3}$ Erasmus School of Law, Criminology, Rotterdam, The Netherlands

\section{Correspondence}

Olaf Simonse, Faculty of Social and Behavioural Sciences, Leiden University, Knowledge Centre Psychology and Economic Behavior, Leiden, The Netherlands.

Email: o.simonse@fsw.leidenuniv.nl

Funding information

Ministry of Finance - Netherlands

\begin{abstract}
Social welfare aims to support financially vulnerable households by protecting them from financial shocks and providing them with a basic standard of living. Many eligible households, however, do not take up social welfare. We present the results of in-depth interviews with 31 members of financially vulnerable households in two large Dutch cities about their experiences with welfare. We examined the role of money in their lives, what inhibited them from taking up social welfare, and how they sought support. For many interviewed households, money was a source of stress. The fear of reclaims and mistrust of government institutions were the main inhibitors to participating in welfare programs. Whereas the experience of shame and stigma were substantial inhibitors for claiming local welfare benefits, they were not for participating in national welfare programs. Formal and informal help promoted welfare participation, but many participants lacked access to both. We discuss policies that could decrease the perceived uncertainty of benefits receipt and give directions for future research.

KEYWORDS

Netherlands, non-take-up, social security
\end{abstract}




\section{1 | INTRODUCTION}

With child support, I had to repay everything. As I said, I worked through an employment agency, so I don't have one salary. Sometimes I earned more; other times, I earned less. That was a fact of life. [...] At the end of the year, I got a blue envelope in my mailbox. I had to pay back $€ 1.500$. I thought: "how is that possible?" [...] I had to repay $€ 150$ every month. But if I earned $€ 1.200-€ 1.300$ per month, that was very difficult.

This excerpt is from our interview with a single mother on the weekly street market in a deprived neighbourhood in The Hague, the Netherlands. During the interview, she cheered up when she told us that she had recently received a fixed contract, providing her with a stable income. She explained why she no longer used any benefits, despite being eligible. Her story was illustrative of our conversations with financially vulnerable households for the current study.

Relative poverty has profound implications on mental and physical health (Adler \& Snibbe, 2003; Ridley et al., 2020). Research shows that being relatively poor is linked with feelings of uncertainty, stress and shame (Sen, 1983; Underlid, 2007; Van Dijk et al., 2022). Welfare systems aim to decrease financial distress by providing income security for the population after adverse events such as illness, unemployment, retirement, and death (Dubois \& Ludwinek, 2015). Yet, many eligible households do not participate in the welfare programs. Non-take-up rates vary between countries and programs, but 30\%-40\% rates are not exceptional (Dubois \& Ludwinek, 2015; Hernanz et al., 2004; Plueger, 2009). This means that welfare systems do not achieve their goals, which may undermine their legitimacy (Odum, 1923) and increase inequality (Hernanz et al., 2004). For individual households, not participating in welfare lowers their wellbeing and may exacerbate poverty (Vrooman \& Asselberghs, 1994).

Theoretical and quantitative studies have identified numerous potential inhibitors for welfare participation, including welfare stigma (Handler \& Hollingsworth, 1969; Moffit, 1983; Odum, 1923), transaction costs, learning costs, psychological costs (Currie, 2019; Moffit, 1992; Mood, 2004), administrative burden, fear of reclaims, and lack of social support (Bertrand et al., 2000; Christensen et al., 2020; Garthwaite, 2014; Mood, 2004; Rege et al., 2012). Promotors of welfare participation include knowledge of program criteria, perceived eligibility, and perceived utility (Craig, 1991; Kerr, 1982; Van Oorschot, 1994). It is well-established that more complex systems with more eligibility criteria go hand-in-hand with a smaller fraction of the eligible population participating (Van Oorschot, 1991). This generates a paradox: more targeted social welfare development results in more stringent rules and, hence, lower take-up, which likely disproportionally affects the most financially vulnerable.

There is evidence that formal and informal support may stimulate welfare participation (Bertrand et al., 2000; Finkelstein \& Notowidigdo, 2019). But there is little research on how the financially vulnerable find formal and informal support when needed. Several studies have shown, however, that feelings of mistrust and shame are higher among groups with lower socioeconomic statuses (Hamamura, 2012; Sen, 1983; Walker et al., 2013). Mistrust and shame may well inhibit help-seeking behaviour.

Few studies have examined how eligible households, especially financially vulnerable ones, experience welfare participation. Understanding these experiences may help develop more inclusive social welfare systems that better target needy households. To this end, the current study aims to grasp the lived experiences of financially vulnerable households eligible for benefits. It captures their experiences of being financially vulnerable, what inhibits them from using welfare, and where they turn for help when needed.

The remainder of this article is organised as follows. We start with an overview of the literature on welfare participation (Section 2). Then, we describe the methodological approach (Section 3) and the results (Section 4). We end with conclusions, implications for policy and directions for further research (Section 5). Data S1 provide background on the Dutch system for income support and the two interview locations (The Hague and Eindhoven) and contain the interview guide. 


\section{WELFARE PARTICIPATION LITERATURE}

\subsection{Financial vulnerability}

Even in affluent welfare states, being financially vulnerable brings insecurity and fear (Underlid, 2007). Low socioeconomic status is strongly related to stress and rumination (De Bruijn \& Antonides, 2020; Johar et al., 2015; Van Dijk et al., 2022). There is ample evidence of the impact of financial vulnerability on mental and physical health (Adler \& Snibbe, 2003; Haushofer \& Fehr, 2014; Netemeyer et al., 2017; Ridley et al., 2020). A recent line of literature suggests that the subjective feeling of financial scarcity impedes cognitive functioning. Decreased cognitive performance may negatively affect subsequent behaviours, such as saving, borrowing, and investing, thus exacerbating financial vulnerability (Mani et al., 2013; Mullainathan \& Shafir, 2013).

\subsection{Promotors and inhibitors of welfare participation}

Initially, the study of welfare participation was pre-eminently the domain of social policy and public administration research. The first studies focused on welfare stigma, which has maintained a prominent role in the literature. Scholars started to systematically include other causes of non-take-up of welfare in the 1970s. For example, based on a literature review, Craig (1991) concluded that some groups do not claim due to 'some mixture of pride, ignorance, a sense of stigma, reluctance to make the efforts a claim calls for, a desire for self-sufficiency on the part of an individual or family, an unwillingness to become involved with a government agency and a feeling that the whole business is not worthwhile' (p. 543). Around the same time, Van Oorschot (1994) presented a comprehensive framework that integrated a range of promoters and inhibitors of welfare take-up. According to his model, potential claimants must pass certain thresholds (knowledge and perceived eligibility) before making a trade-off between promoting factors, such as perceived need, and inhibiting factors, such as negative attitudes towards welfare.

Another primary line of welfare participation research comes from economics. Economic models have examined the issue by balancing welfare participation's benefits (utility and need) and costs (transaction costs, learning costs, psychological costs, and stigma) (Anderson \& Meyer, 1997; Currie, 2019; Moffit, 1992).

Behavioural insights have contributed significantly to the welfare participation literature in the last decade. Public administration scholars now realise that administrative burden, defined as 'an individual's experience of policy implementation as onerous', looms larger for citizens with less human capital and thus increases inequality (Christensen et al., 2020; Herd et al., 2013; Moynihan et al., 2015, 2016). Behavioural economists have developed interventions to counteract psychological inhibitors of welfare participation, such as unawareness, informational complexity, and (non-cognitive) application costs (Bhargava \& Manoli, 2015; Deshpande \& Li, 2019; Domurat et al., 2021; Finkelstein \& Notowidigdo, 2019).

\subsection{Support and help on financial matters}

Studies show that formal and informal support help may promote welfare participation (Bertrand et al., 2000; Finkelstein \& Notowidigdo, 2019). Few studies have examined how financially vulnerable households go about seeking help. From a theoretical perspective, there is reason to suspect that financially vulnerable households may experience thresholds for seeking help. Evidence shows trust is lower among financially vulnerable households in affluent countries (Hamamura, 2012). Also, relative poverty brings shame (Sen, 1983) and social exclusion (Kabeer, 2000). 


\section{$2.4 \quad$ The current study}

The academic literature on welfare participation tends to be theoretical, and most empirical studies in this area are quantitative. Quantitative research has the advantage of providing generalisable knowledge. It often lacks, however, depth and context (Plano Clark \& Ivankova, 2017). Many important characteristics of people and communities cannot be meaningfully reduced to numbers or adequately understood without reference to the local context in which people live (Choy, 2014). Examples of such characteristics are identities, perceptions, and beliefs. In the case of social welfare, it seems especially worthwhile to better understand the experiences of financially vulnerable households with welfare participation. This understanding may help the development of inclusive social security systems that have a bigger chance of reaching their goal of supporting the financially vulnerable. Many studies have focused on the experiences of the financially vulnerable. Still, they do not apply a systematic approach to welfare dependence and participation, as in the nontake-up phenomenon. The current study examined the lived experiences of financially vulnerable households with welfare participation. It aimed to reveal what it means to be financially vulnerable, which barriers financially vulnerable households experience when applying for benefits, and where they find help (Box 1).

\section{3 | METHODS}

The current study was part of a qualitative research program of the Dutch Ministry of Finance to gather the experiences of financially vulnerable households with different aspects of personal finances. We collected data through indepth interviews to capture the experiences of financially vulnerable groups, who are less likely to participate in quantitative studies and thus risk marginalisation (Plano Clark \& Ivankova, 2016, 2017). Our research objectives fit best with an interpretative phenomenological epistemology (Willig, 2013). We chose an interpretative research paradigm rooted in the phenomelogic and hermeneutic research traditions (Boeije, 2009; Giorgi, 2005; Van Manen, 2014).

\section{BOX 1 Income support in the Dutch Welfare System (see Data S1 for details)}

Local benefits. The Participation Law (Participatiewet) mandates local municipalities to move people towards the active labour force and aims mainly at the unemployed and those with meagre incomes (Ministry of Internal Affairs, 2019). Programs under the Participation Law tend to have strict eligibility rules, such as the obligation to search for jobs. Non-take-up rates for these programs vary significantly between different provisions and municipalities.

National benefits. The three primary national income support programs are healthcare, rent, and child support benefits. These programs target many in the population. The take-up rates were between $84 \%$ and $90 \%$ in 2018. Childcare benefits provide financial means that enable working parents to hire childcare. For all four programs, applicants receive an advance payment based on their estimated income, which is settled at the end of the year. This mechanism results in a large number of retroactive corrections. In 2018 , there were 2.3 million reclaims.

The benefits scandal. Between 2005 and 2017, the tax office unjustly accused around 30,000 households of fraud with childcare benefits. Households were required to repay large sums of received benefits, often causing severe debts and a cascade of problems in all areas of their lives, such as loss of job or home, relocation of children, and mental and physical health problems. The scandal has received a lot of media coverage. 


\section{1 | Study participants}

A team of four trained and experienced interviewers (one female and three males) conducted the interviews. We performed the interviews in pairs of varying compositions. Working with two interviewers could be helpful or intimidating for the participants in discussing potentially sensitive subjects. Following Monforte and Úbeda-Colomer (2021), we felt that working in pairs would enable us to build rapport, set a good atmosphere, and manage awkward silences. One interviewer would start the interview and follow the interview guide. The other interviewer would focus on taking notes, observing the conversation, and asking curiosity-driven questions as the interview progressed.

The sample was diverse in terms of household composition (couples, singles, divorced, widowed; with and without children), income situation (student, employed, self-employed, unemployed, disabled, and retired), and cultural backgrounds (with and without migration backgrounds). Of the 24 interviews, we excluded three because the participants-relatively wealthy couples-did not belong to the target group of our study. Of the remaining 21 interviews, 12 were with one participant, eight with two participants, and one with three participants. The interviews took between 20 and 55 min. See Table 1 for an overview of the sample.

The interviewers came from different socioeconomic and cultural backgrounds than most interviewees. These background differences might result in prejudices in both directions and distance between interviewers and interviewees. To address these potential issues, the interviewers discussed them at the start to raise awareness of them. Also, during the interviews, they paid ample time and attention to creating an atmosphere of trust and equality and practised active listening without prejudice.

\section{2 | Participant recruitment}

We recruited and interviewed people in a weekly street market in a deprived neighbourhood in The Hague and the city centre of Eindhoven (see Data S1 for details).

We chose places that attracted a broad audience with diverse socioeconomic and cultural-ethnic backgrounds and where people were not in a hurry. Representativity was not an aim of our sampling strategy; however, we did

TABLE 1 Overview of participant characteristics

\begin{tabular}{|c|c|c|c|}
\hline & The Hague & Eindhoven & Total \\
\hline \multicolumn{4}{|l|}{ Gender } \\
\hline Male & 6 & 3 & 9 \\
\hline Female & 10 & 12 & 22 \\
\hline \multicolumn{4}{|l|}{ Work status } \\
\hline Employed & 10 & 4 & 14 \\
\hline Housewife & 1 & 1 & 2 \\
\hline Retired & & 3 & 3 \\
\hline Self-employed & 3 & 2 & 5 \\
\hline Student & 1 & & 1 \\
\hline Unemployed & 1 & 5 & 6 \\
\hline \multicolumn{4}{|l|}{ Cultural background } \\
\hline Migration background & 4 & 6 & 10 \\
\hline Native Dutch & 12 & 9 & 21 \\
\hline \multicolumn{4}{|l|}{ Single or couple } \\
\hline Couple & 11 & 6 & 17 \\
\hline Single & 5 & 9 & 14 \\
\hline
\end{tabular}


strive for a diverse sample to obtain experiences from various groups. We recruited potential participants in the streets by asking them whether they wanted to share their experiences of making ends meet.

We informed participants that the general goal of the research was to capture their personal experiences with financial matters. We did not reveal our interest in non-take-up until the debriefing stage to obtain their unbiased and spontaneous responses. In both locations, we interviewed participants until we reached a saturation point, jointly decided by the interviewers. We offered no monetary compensation because we wanted to include intrinsically motivated participants to share their experiences. All participants provided informed consent.

\subsection{Data collection}

We used semi-structured interviews, making participants feel at ease talking about a potentially sensitive subject (Fontana \& Frey, 2000). Also, semi-structured interviews enabled us to address theoretically driven variables while providing room for lived experience (Galletta, 2013) and to explore the context-specific variation between households (Boeije, 2009; Kvale, 1996).

We held the interviews in public places with an informal ambience, at the same time ensuring privacy. To create a homely setting, we set two tables (one inside, one outside) with attributes, such as a tablecloth. To ensure privacy, we set interview tables beyond hearing distance of the other tables. Being aware that the Ministry of Finance might encounter distrust and distance, we took ample time to create an open atmosphere. We stressed that we wanted 'real stories; not the opinions of civil servants or scientists, but the experiences of people who know what life looks like'. We also explained to participants how we ensured their privacy and that they could refrain from answering questions or stop their participation at any time without negative consequences. To ensure that participants were at ease, we first asked them to describe themselves (their household composition, daily activities, et cetera) and offered coffee, tea, or a soda.

We used a simple language interview guide (see Data S1) to ensure that the participants understood the questions. The interviews consisted of open-ended questions in three blocks. The first block aimed to collect participants' thoughts and feelings about money and its role in their daily lives. It included experiences with making ends meet, borrowing, and saving. The second block captured potential inhibitors for claiming benefits. In the third and final block, we asked participants if and how they looked for help when they could not figure out financial matters themselves.

We planned an evaluation of the interview guide after the first four interviews to update it if needed. In the evaluation, we concluded that relatively much time was spent on the first block, after which little time was left for our study's primary focus. Therefore, we decided to spend more time on the second block from the fifth interview onwards.

We revealed that welfare participation was our prime research interest at the debriefing stage. Because participants could perceive the research subject as sensitive, extra care was given to potential stress or other negative emotions during the debriefing stage to prevent harm. We recorded the interviews and transcribed them non-verbatim; we removed elements such as interview noise, corrected grammar, and stutter from the transcriptions (Oliver et al., 2005).

\section{4 | Data analysis}

At the end of both field days, the interviewers discussed themes that had emerged during the interviews. The first author coded the interviews using ATLAS.ti version 9. In the first iteration, he read the transcripts while listening to the audio recording, capturing nuances not visible in the transcriptions, such as hesitations, lapses, interruptions, and emotions. He followed an iterative process of reading and analysis. He used deductive and inductive analysis: the predefined set of codes was expanded as new themes emerged (see Data S1) (Abramson et al., 2018). After reading all the interviews, he performed an integrative analysis. He collected emerging themes and made connections by performing thematic co-occurrence analysis (Scharp, 2021). He then had a session with the other three interviewers to reflect on the emerging patterns. 


\section{4 | RESULTS}

We observed that, after some initial hesitation, people talked openly about their finances, life events, and experiences with benefits. Some showed anger and sadness when talking about their experiences with money. One participant indicated she did not want to talk about her financial experiences. After suggesting to her to stop the interview, she decided to continue. On one occasion, an interviewee showed signs of potential distress. We took extra time to talk to her. She told us that talking about money evoked negative emotions. After expressing her feelings, the distress lessened, and she told us she was okay.

\section{1 | Money experiences}

\subsection{1 | Associations with money}

We asked participants to mention the first thing that came to mind when we said 'money'. Most participants had negative thoughts and feelings about money, associating money with sadness, pain, and difficulties making ends meet. One participant described this as 'one big fight'. Another compared money with a 'punishment'. One participant said:

Two for the price of one. That is what comes to mind. And food that you can buy but don't want to eat. Buying the cheapest vegetables. Not because you like them, but because you can buy them.

For many participants, stress was the dominant feeling associated with money. Some spontaneously mentioned 'panic'. A considerable number of participants linked money to health problems. For example, one participant told us that she could not afford to go to the dentist and had terrible teeth. She could hardly chew and said, "I am ashamed to smile'. Negative attitudes towards money were more common among self-employed and unemployed, those with a migration background, those with fluctuating incomes, and single participants (either divorced or otherwise).

When participants mentioned positive experiences with money, these mainly included the absence of stress and not worrying. Some mentioned that money gave them a feeling of freedom and the ability to do nice things, such as vacations and outings. Others had ambivalent or neutral associations with money. One female participant (Willig, 2013), for example, spontaneously said 'heaven and hell' when we asked to mention the first thing that came to mind. She explained that she had a love-hate relationship with money by saying:

Yes, because, as I said, you need money to live. And that can be a great concern. I've had times that I had so little that I could hardly buy food, you know. But on the other hand, money also gives you a lot of freedom, of course.

She told us that-if she had more money-she would help poor people. And for her, having more money was associated with not worrying.

\subsection{2 | Financial behaviour}

\section{Balancing income and expenditures}

Many participants indicated that they had difficulties making ends meet. These difficulties were closely related to negative associations with money, especially stress and worries, and were more common among the unemployed and self-employed. For the unemployed, this finding is likely due to low incomes, whereas income fluctuation may 
play a role for self-employed participants. For most couples, at least one of the two had a paid job, which made difficulties making ends meet less common among couples.

\section{Borrowing and debts}

Most participants had very negative attitudes towards debt. These negative attitudes were strong for those who had experiences with debts, as one divorced woman told us:

The last years of my marriage were terrible financially. And then with bailiffs at the door. And I never ever want that again. So I make sure that I make ends meet. Then if necessary, I eat bread for a few days, but I will never get indebted again. I know what that results in.

Participants generally indicated that they preferred borrowing from a relative to borrowing from an institution. Sometimes, participants did not see a loan from a relative as a 'real' debt. Participants generally regarded a debt to the tax administration very negatively. This negative view seemed to result from the 'harshness' of the tax administration in reclaiming debts. A few participants were still heavily indebted. One young mother told us that her debts totalled $€ 100,000$. These debts were mainly due to not paying rent, and the tax administration reclaimed unjustly paid childcare benefits. She was at peace with the fact that a curator managed her finances. This gave her 'rest', although she would like to manage her own finances again in the future because this would make her feel proud of herself.

\section{Financial buffers and savings}

Most participants indicated having some financial buffer to cover unexpected expenditures, such as replacing a broken fridge. Some only had minimal buffers that were insufficient to cover setbacks. A few participants indicated that they were unable to save at all. Self-employed had more buffers than employed, who, in turn, had more buffers than unemployed participants. Respondents with current or recent unemployment had the lowest buffers. Singles had fewer buffer savings compared to couples and divorced participants. Some participants had a buffer in the form of a relative they could always fall back on. Such a buffer protected them against unexpected expenditures and financial stress.

\section{Meeting financial challenges}

When asked how they dealt with their financial challenges, most participants spontaneously mentioned that they cut spending, for example, by refraining from going on holidays or not buying clothes. Some cut spending at the cost of their health. For example, one participant indicated that she needed orthotics but could not afford them. Another participant, as described above, had stopped going to the dentist, which had resulted in bad teeth. Yet another participant indicated that she had to take a non-diversified diet depending on what was on sale in the supermarket: 'Sometimes I just eat potatoes the whole week'. In addition to cutting spending, generating additional income, for example, by working more hours, was also mentioned quite often.

\subsection{Experiences with welfare participation}

\subsection{1 | Fear of reclaims}

The most mentioned reason for not using benefits was fear of reclaims. This fear was often realistic: many participants had previously experienced reclaims. They wanted to avoid the stress of having to repay a received benefit afterwards. A young couple without children said:

Indeed, when I got that letter, plus that invoice for last year, and saw the amount that I had to repay, then I thought: I immediately quit [using benefits]. 
None of the participants was a victim of the benefits scandal. Only two participants mentioned the benefits scandal, but it did not seem to contribute to their fear of reclaims. Notably, the fear of a reclaim often co-occurred with general financial stress. Participants talked about benefits as if they represented a loan. A retired 74 years old painter did not apply for benefits anymore because of a reclaim in the past. Instead, he still worked for his son's company and as a self-employed painter to acquire sufficient income. A self-employed woman of 56 had recently borrowed $€ 600$ from her sister to pay for her son's study trip. At the same time, she did not apply for healthcare and rent benefits, although she was eligible. Only one of the participants was aware of the possibility of applying for benefits retroactively after one's yearly income is known. The fear of reclaims was present amongst participants of varying background characteristics. It was more common, however, for self-employed and for divorced participants. Unemployed participants had relatively little experience with reclaims. Some unemployed participants told us they received help from the social service with their application. Also, those unemployed for a more extended period had no fluctuation in their incomes and ran no risk of having to repay benefits.

\subsection{2 | Negative attitudes towards government}

Many participants had a negative attitude towards the government and the tax administration. We did not ask for this explicitly; this theme emerged during the interviews. Participants indicated that the government had not helped them when they needed help in the past. Also, they indicated that the tax administration had made mistakes, resulting in reclaims. A typical example involved a divorced woman without children:

Yes, I felt left alone. Even a bit discriminated against. And very sad. Really very sad, yes. You expect ... I really needed help. I've always been able to do everything myself. And then I couldn't because of the circumstances. [...] And if you are left out in the cold like that, then I think, yes, so many other people dó get help.

There was a clear link between reclaims and mistrust in the tax administration. Many participants felt that the tax administration is responsible for ensuring that people receive the correct benefits amount since 'they know everything about you'. Negative attitudes towards the government were powerful among native Dutch participants. Participants with a migration background less often showed negative attitudes towards the government. Two groups that stood out in mistrust against the government were self-employed and divorced participants.

\subsection{3 | Lack of knowledge}

Some participants lacked knowledge about the benefits they could receive. However, we did not find this a primary cause of non-take-up. Lack of knowledge was often the consequence of the absence of the necessity of knowing because someone else-for example, children or a professional-took care of the benefits application. Others did not seek information about benefits because they said they did not need them or did not want to 'scrounge'. Lack of knowledge was more common among native Dutch participants.

\subsection{4 $\quad$ Administrative burden}

Participants often mentioned the administrative burden associated with social security. However, this administrative burden did not relate to the application process for national benefits, which most participants perceived as very easy. The application for other-often locally administered-welfare programs was experienced as more burdensome. 
Some participants mentioned that 'the government wants to know everything about you', which humiliated them. The administrative burden for national benefits was often associated with updating information with the tax administration whenever one's situation changed. Participants mentioned that this required continuous attention because they ran the risk of receiving a reclaim. This caused a cognitive load and-on some occasions-stress:

... Because I've done this [applied for healthcare benefits] and then, it changed again, because you earn more then suddenly your benefits will change. So you go from $€ 12$ to $€ 9$ to $€ 4$, and at the end of the year, I have to repay $€ 180$. I'm not in the mood for this! For a few euros. [...]. So you continuously need to keep track of what you're doing. If you don't ... many people just fill it in once and think whatever. And then you get into problems.

Notably, the experience of administrative burden was more common for native Dutch participants (compared with participants with a migration background). Unemployed hardly suffered from administrative burden because a professional took care of the application and administration of their benefits, and their eligibility was relatively stable.

\subsubsection{Stigma and shame}

Few participants reported stigma or shame as an inhibitor of welfare participation. Many participants explicitly mentioned that shame played no role in participating in a national benefits program for which one is eligible. Some participants indicated that they could imagine someone being ashamed to apply for benefits, but no participant reported feeling shame about welfare participation themselves. Their rationale was that national benefits are broadly used, and employed citizens are also eligible. Stigma and shame seemed to play a more prominent role in other welfare programs, for example, unemployment benefits and the Food Bank. This was especially the case for native Dutch participants. For example, one young woman said:

[...] requesting unemployment benefits feels like a shortcoming. It should not be necessary. You should be able to earn your own money, be self-reliant. And not feel like not being capable of something normal.

\subsubsection{Other inhibitors}

Participants mentioned several other potential inhibitors for claiming welfare. For example, some participants experienced a lack of freedom when participating in a welfare program. Others mentioned the pressure to meet the eligibility criteria; this applied to local rather than national benefits. On some occasions, language barriers and digital illiteracy played a role, especially for those who did not get support from a professional or a relative. Some thought they were ineligible for benefits. We could not check whether this was the case. Based on our best estimate, the perception was correct in some instances and wrong in others. In any case, perceived eligibility did not seem to be a significant benefit threshold in our sample. Finally, two participants indicated they were against using benefits because they disagreed with government policy, specifically around COVID-19.

\section{3 | Getting help}

Friends and relatives were most often mentioned as a source of help. Quite a few participants got help from a professional, such as a curator (in the case of unemployment or overindebtedness) or bookkeeper (for self-employed 
participants). Others got help from the local government, especially in Eindhoven. A considerable number of participants mentioned We Eindhoven as a source of help. We Eindhoven is an initiative of the municipality that offers inhabitants who temporarily need support to get a grip on their life. One refugee mentioned receiving help from the Council for Refugees. Some of our participants also provided financial help as a professional, relative, or friend.

Participants also mentioned barriers to seeking help. Many had had bad experiences seeking but not receiving help from the government in the past. Some mentioned that they had to overcome shame to seek help, but that did not stop them from asking. A few participants did not know where to go for help.

\subsection{Differences between the two locations}

Although the general findings apply to both locations, we noticed some differences. Negative associations with money, including stress, were more common in our interviews in The Hague, whereas neutral and ambiguous associations were more common in our interviews in Eindhoven. This coincides with the finding that more participants in The Hague had difficulties making ends meet and negative experiences with borrowing and debts. The fear of reclaims was also more prominent for participants from The Hague. Participants in Eindhoven found the application easier than participants from The Hague. No participants mentioned the local service point in The Hague; in Eindhoven, many knew the local service point (We Eindhoven).

\section{5 | DISCUSSION}

We interviewed 31 financially vulnerable people about their experiences with welfare participation. We examined money's role in their lives, the inhibitors they experienced for taking up benefits, and where they sought help if needed. We observed a high level of disclosure on sensitive financial subjects. We suspect that the effort spent on building report, creating an open atmosphere and asking open-ended questions ('What is the first thing that comes to mind when I say "money"'?) stimulated interview participants to talk freely about their financial affairs.

Our study complements the growing body of-mainly quantitative-literature on the association between financial vulnerability, stress, and mental health (e.g., Adler \& Snibbe, 2003; De Bruijn \& Antonides, 2020; Drentea \& Lavrakas, 2000; Halliday, 2008; Ridley et al., 2020) by revealing the lived experiences of the financially vulnerable. For them, money struggles are ubiquitous in their everyday lives. Many associated money primarily with stress; they worried about making it through the end of the month, being able to buy (healthy) food, or getting the health care that they needed. They associated having money with being stress-free.

For financially vulnerable individuals-especially those with low, fluctuating incomes-the fear of reclaims was strongly related to welfare participation. Many had experienced reclaims, and fear of reclaims was the most common reason for not applying for national benefits. The fear of reclaims may be more salient for those in low-paid jobs because the possible reclaim amounts are larger and have a larger impact, given their lower incomes. As a result, those at the lower end of the labour market may experience a threshold for seeking work, which may sustain inequality and poverty. This threshold for entering the labour market may also be stronger for women, who are more likely to take on care responsibilities. Thus, the fear of reclaims may contribute to sustaining income and gender inequalities.

To our surprise, participants rarely mentioned the benefits scandal. Despite its broad media coverage, the scandal did not seem to play a prominent role in the decision of our participants to take up benefits. A few participants mentioned the scandal but indicated it had not affected their behaviour. Although participants did not mention the benefits scandal as a reason for not using benefits, it is conceivable that the media attention on the subject negatively affected trust in government and, thereby, indirectly discouraged welfare participation. The scandal shows resemblance with the Australian Robodebt scandal, in which hundreds of thousands of welfare recipients got 
unjustified reclaims based on faulty computer algorithms (Whiteford, 2021). Studies indicate that these reclaims have resulted in confusion, hardship, anxiety, stress, and depression (Huggins, 2019; Millar \& Whiteford, 2020). Some authors have placed the Robodebt scandal in the broader context of the digitalisation of welfare assignment, where computers, instead of humans, take decisions on welfare eligibility. This digitalisation has resulted in a shift of administrative burden from the government towards the individual and increased unpredictability of welfare receipt, which primarily hits the vulnerable (Human Rights Watch, 2020; Rinta-Kahila et al., 2022). Given this trend, it would be worthwhile for future studies to examine the effects of welfare digitalisation, reclaims and scandals on trust and welfare participation.

Participants experienced benefits as a loan from the tax administration. With advance payments based on an estimate of future income, the current benefits system seems to increase rather than decrease financial insecurity for financially vulnerable households. This runs counter to the intention of social welfare but corroborates findings from the United Kingdom and Australia, where the unpredictability of benefits seems to decrease their perceived integrity (Millar \& Whiteford, 2020). In line with these findings, financially vulnerable households tended to have a negative attitude towards the government, including the tax administration. Participants had experienced that the government did not help them when they needed help and had made mistakes that had resulted in unexpected reclaims, which, in turn, had caused financial worries. These findings align with the large body of literature indicating that debts (Drentea \& Lavrakas, 2000) and income shocks (Halliday, 2008; Lichand \& Mani, 2020; Ridley et al., 2020) increase financial stress and decrease mental health.

Although the literature often mentions stigma and shame as a reason for forgoing benefits (Handler \& Hollingsworth, 1969; Moffit, 1983; Odum, 1923), participants in the current study seldom mentioned stigma or shame concerning national benefits. This is likely due to national benefits being available for a broad population group, including those with jobs. Another possibility is that participants were ashamed to talk about their shame. Several participants said that they could imagine someone else feeling ashamed or stigmatised for using benefits, which might be an indication of them projecting their shame on others. At the same time, we found that participants displayed a high level of disclosure on other sensitive topics. Also, stigma and shame were mentioned for local benefits such as unemployment benefits, for which one must visit social services and physically reveal personal information about oneself. In contrast to national benefits, local benefits are associated with being unemployed and unable to take care of oneself. This finding corroborates earlier findings that perceived stigma is larger for local welfare schemes (Ko \& Moffitt, 2022). In sum, stigma and shame play a limited role in relatively anonymous programs for large segments of the population, including those who work. In contrast, stigma and shame may be felt if participating in more visible programs that may signal that one cannot look after oneself.

In the literature on welfare deservingness, scholars consistently find that the general population see migrants as the least deserving group (Reeskens \& van der Meer, 2019; Van Oorschot, 2006). We would, therefore, have expected migrants to experience more welfare stigma and more mistrust of government. We did not, however, find explicit or latent indications that this might have been the case. On the contrary, we observed less mistrust in government among migrants compared to native Dutch. Despite the attention we dispensed to the interview setting to provide comfort and trust, this may have resulted from interviewer effects. Because the government promoted the research, migrants may have been more hesitant to speak their minds than the native respondents. The welfare experience of migrants is a relevant area for future research, mainly because the support for equal welfare provision to migrants seems to have declined further due to the growing number of asylum seekers and the call for austerity measures after the last economic crisis (Jørgensen \& Thomsen, 2016; Kootstra, 2017). Participants often mentioned administrative burden and fuss. For national benefits, this was not related to the application process but to continuously needing to be alert to administer changes in their situations to prevent reclaims. This finding fits into a growing body of theoretical and quantitative literature arguing that administrative burden affects vulnerable groups more than others (Christensen et al., 2020; Martin et al., 2022). Participants reported pressure to meet the eligibility criteria for local benefits and the humiliation and stigma associated with disclosure. These aspects did not seem to play a role in national benefits. 
Some groups readily had access to professional help, such as the unemployed and the overindebted, migrants and people with a broad social network and self-employed who could afford a bookkeeper. But those without such a safety net, such as financially vulnerable entrepreneurs and divorced women, had an additional financial vulnerability and an increased risk of non-take-up. This finding corroborates earlier findings that social support may enhance welfare participation (Bhargava \& Manoli, 2015; Daponte et al., 1999; Finkelstein \& Notowidigdo, 2019).

There were notable differences between the two locations. We offer two potential explanations. First, the location in The Hague, a local street market in a poor neighbourhood, may have attracted more financially vulnerable citizens. The location in Eindhoven, the city centre, likely attracted a broader audience. Although we recruited people who had experienced difficulties making ends meet, our sample included more financially vulnerable citizens in The Hague, such as unemployed and low-income self-employed individuals. In Eindhoven, relatively more participants were employed. Second, the strong position of We Eindhoven as an organisation that helps people get a (financial) grip may have contributed to decreasing the financial distress of the financially vulnerable.

The findings in this article give insights into the lived experiences of an important target group for social welfare that can guide policy and future research. We reveal the experiences of a group that often does not participate in quantitative studies. The findings of our study underscore that policymakers must develop welfare systems with the target population-usually the financially vulnerable-in mind. Rather than basing assumptions of research and policy only on professional respondents, it is worthwhile to invest the effort to collect the perspectives and experiences of financially vulnerable groups themselves.

An important consequence of our findings in the context of social welfare systems that work with advanced payments is that these cause unpredictability and stress for the participants. Overpayments are inherent to meanstested welfare systems responsive to household welfare needs (Millar \& Whiteford, 2020). At the same time, OECD observes a trend of increasing income volatility and proposes that a key priority of social welfare systems is 'making protection sufficiently agile to respond to changes in people's need for support' (OECD, 2019). There is little research on the effects of reclaims on take-up of benefits and trust in the welfare system. Scholars have proposed ways to prevent overpayments or mitigate their effects, such as waivering reclaims or making it easier to report changes (Millar \& Whiteford, 2020). However, the effectiveness of such interventions has not yet been tested. Thus, here lies an important opportunity for further research.

Our study shows that a lack of trust in government institutions inhibits welfare participation. Increasing trust in government and tax administration may contribute to welfare participation. Citizen-centred welfare policies, characterised by a focus on the quality of the service to citizens rather than a focus on rules, procedures, and constraints, are one possible way of achieving this (Doherty et al., 2021; Kernaghan, 2000). For example, using 'local helpers', either by stimulating informal support or creating an easily accessible professional support facility, may be a viable way to increase trust and welfare participation. Those closer to the financially vulnerable have a bigger chance of increasing the confidence of this group in their right to help them overcome the stress of potential reclaims. They can assist them in monitoring their financial situation and informing the tax administration about changes, thus decreasing the administrative burden of welfare participation.

Future studies could examine interventions using the findings of this article. For example, experiments to reduce unpredictability could give valuable insights. One way of achieving this is to stimulate retroactive benefits application. Another could be to make updating personal information easier for welfare recipients. In the interviews for this study, we found that fear of reclaims and trust in government institutions inhibit financially vulnerable citizens from participating in welfare. To increase the generalizability of these results, it would be worthwhile to test them in quantitative studies. Finally, extending the research to welfare participants in other countries would be valuable.

We hope that the current study reminds policymakers of the importance of considering the challenging circumstances of financially vulnerable households when designing welfare policies. This is essential if welfare policies are to achieve their goals: to provide security to the financially vulnerable. 


\section{ACKNOWLEDGEMENTS}

The authors thank Rick Nijkamp and Dörthe Kunkel of the Ministry of Finance for their participation in the preparation and execution of this study. They thank TrueTalk for organising the field work.

\section{FUNDING INFORMATION}

The field work and the transcriptions for this study were funded by the Money Wise Platform of the Ministry of Finance as part of the MoneyTalks program.

\section{CONFLICT OF INTEREST}

The authors declare no conflicts of interest.

\section{DATA AVAILABILITY STATEMENT}

Data available on request due to privacy/ethical restrictions.

\section{ETHICS STATEMENT}

The Leiden University Psychology Ethics Committee provided approval in advance of the interviews (protocol number V2-2982).

\section{ORCID}

Olaf Simonse (iD https://orcid.org/0000-0001-7588-6465

Gabry Vanderveen (D) https://orcid.org/0000-0001-9082-6647

Lotte F. van Dillen (ID) https://orcid.org/0000-0002-3003-5488

Wilco W. van Dijk (iD https://orcid.org/0000-0002-0106-0297

Eric van Dijk (1D) https://orcid.org/0000-0001-6116-0946

\section{REFERENCES}

Abramson, C. M., Joslyn, J., Rendle, K. A., Garrett, S. B., \& Dohan, D. (2018 Jun 1). The promises of computational ethnography: Improving transparency, replicability, and validity for realist approaches to ethnographic analysis. Ethnography, 19 (2), 254-284.

Adler, N. E., \& Snibbe, A. C. (2003). The role of psychosocial processes in explaining the gradient between socioeconomic status and health. Current Directions in Psychological Science., 12(4), 119-123.

Anderson, P. M., \& Meyer, B. D. (1997). Unemployment insurance takeup rates and the after-tax value of benefits. The Quarterly Journal of Economics., 112(3), 913-937.

Bertrand, M., Luttmer, E. F. P., \& Mullainathan, S. (2000). Network effects and welfare cultures. The Quarterly Journal of Economics., 115(3), 1019-1055.

Bhargava, S., \& Manoli, D. (2015 Nov). Psychological frictions and the incomplete take-up of social benefits: Evidence from an IRS field experiment. American Economic Review., 105(11), 3489-3529.

Boeije, H. R. (2009). In: Hart H't., Hox, J. J. Onderzoeksmethoden (8e, geheel herz. dr. ed.). Boom Onderwijs.

Choy, L. T. (2014). The strengths and weaknesses of research methodology: Comparison and complimentary between qualitative and quantitative approaches. IOSR Journal of Humanities and Social Science., 19(4), 99-104.

Christensen, J., Aarøe, L., Baekgaard, M., Herd, P., \& Moynihan, D. P. (2020). Human capital and administrative burden: The role of cognitive resources in citizen-state interactions. Public Administration Review, 80(1), 127-136.

Craig, P. (1991). Costs and benefits: Abe review of research on take-up of income-related benefits. Journal of Social Policy., 20(4), 537-565.

Currie, J. M. (2019). The take up of social benefits [Internet]. National Bureau of Economic Research; 2004 May [cited 2019 Oct 26]. Report No. 10488. http://www.nber.org/papers/w10488

Daponte, B. O., Sanders, S., \& Taylor, L. (1999). Why do low-income households not use food stamps? Evidence from an experiment. The Journal of Human Resources., 34(3), 612-628.

De Bruijn, E. J., \& Antonides, G. (2020). Determinants of financial worry and rumination. Journal of Economic Psychology, 76, 102233. 
Deshpande, M., \& Li, Y. (2019). Who is screened out? Application costs and the targeting of disability programs. American Economic Journal: Economic Policy., 11(4), 213-248.

Doherty, M., Compagnucci, M. C., Haapio, H., \& Hagan, M. (2021). A new attitude to law's empire: The potentialities of legal design. Legal Design., Law 2021, 1-8.

Domurat, R., Menashe, I., \& Yin, W. (2021). The role of behavioral frictions in health insurance marketplace enrollment and risk: Evidence from a field experiment. American Economic Review., 111(5), 1549-1574.

Drentea, P., \& Lavrakas, P. J. (2000 Feb 1). Over the limit: The association among health, race and debt. Social Science \& Medicine., 50(4), 517-529.

Dubois, H., \& Ludwinek, A. (Eds.). (2015). Access to social benefits: Reducing non-take-up (p. 68). Publications Office of the European Commission [u.a.].

Finkelstein, A., \& Notowidigdo, M. J. (2019). Take-up and targeting: Experimental evidence from SNAP. Retrieved January 23, 2021 from https://doi.org/10.1093/qje/qjz013

Fontana, A., \& Frey, J. H. (2000). The interview: From structured questions to negotiated text. In N. K. Denzin \& Y. S. Lincoln (Eds.), Handbook of qualitative research (2nd ed., pp. 645-672). Sage.

Galletta, A. (2013). Mastering the semi-structured interview and beyond: From research design to analysis and publication. New York University Press (Qualitative studies in psychology).

Garthwaite, K. (2014 Dec). Fear of the brown envelope: Exploring welfare reform with long-term sickness benefits recipients. Social Policy \& Administration., 48(7), 782-798.

Giorgi, A. (2005). The phenomenological movement and research in the human sciences. Nursing Science Quarterly., 18(1), 75-82.

Halliday, T. (2008). Income volatility and health [Internet]. Social Science Research Network. Report No. ID 1136396. Retrieved September 25, 2020 from https://papers.ssrn.com/abstract=1136396

Hamamura, T. (2012). Social class predicts generalized trust but only in wealthy societies. Journal of Cross-Cultural Psychology., 43(3), 498-509.

Handler, J. F., \& Hollingsworth, E. J. (1969). Stigma, privacy, and other attitudes of welfare recipients. Stanford Law Review., 22(1), 1-19.

Haushofer, J., \& Fehr, E. (2014). On the psychology of poverty. Science, 344(6186), 862-867.

Herd, P., DeLeire, T., Harvey, H., \& Moynihan, D. P. (2013). Shifting administrative burden to the state: The case of medicaid take-up. Public Administration Review, 73(s1), S69-S81.

Hernanz, V., Malherbet, F., \& Pellizzari, M. (2004). Take-up of welfare benefits in OECD countries, 17. Retrieved from https://www.oecd-ilibrary.org/content/paper/525815265414

Huggins, A. (2019). We need human oversight of machine decisions to stop robo-debt drama [Internet]. The Conversation. The Conversation Media Group Ltd. Retrieved June 7, 2022 from https://theconversation.com/we-need-humanoversight-of-machine-decisions-to-stop-robo-debt-drama-118691

Human Rights Watch. (2020). Automated hardship. How the tech-driven overhaul of the UK's social security system worsens poverty [Internet]. Retrieved from https://www.hrw.org/sites/default/files/media_2020/09/uk0920_web_ O.pdf

Johar, G., Meng, R., \& Wilcox, K. (2015). Thinking about financial deprivation: Rumination and decision making among the poor. ACR North American Advances [Internet]. NA-43. Retrieved January 19, 2020 from https://www.acrwebsite.org/ volumes/1020157/volumes/v43/NA-43

Jørgensen, M. B., \& Thomsen, T. L. (2016). Deservingness in the Danish context: Welfare chauvinism in times of crisis. Critical Social Policy., 36(3), 330-351.

Kabeer, N. (2000). Social exclusion, poverty and discrimination towards an analytical framework. IDS Bulletin., 31(4), 83-97.

Kernaghan, K. (2000). The post-bureaucratic organization and public service values. International Review of administrative sciences., 66(1), 91-104.

Kerr, S. A. (1982). Differential take-up of supplementary pensions: An approach from cognitive psychology [Internet]. https://era.ed.ac.uk/handle/1842/19011

Ko, W., \& Moffitt, R. (2022). Take-up of social benefits. [preprint].

Kootstra, A. (2017). Us versus them: Examining the perceived deservingness of minority groups in the British welfare state using a survey experiment. In The social legitimacy of targeted welfare (pp. 263-280). Edward Elgar Publishing.

Kvale, S. (1996). InterViews: An introduction to qualitative research interviewing. Sage (Inter views).

Lichand, G., \& Mani, A. (2020). Cognitive droughts (Working Paper) (341). University of Zurich, Department of Economics

Mani, A., Mullainathan, S., Shafir, E., \& Zhao, J. (2013 Aug 30). Poverty impedes cognitive function. Science, 341(6149), 976-980.

Martin, L., Delaney, L., \& Doyle, O. (2022). Everyday administrative burdens and inequality. Geary Institute, University College Dublin. 
Millar, J., \& Whiteford, P. (2020). Timing it right or timing it wrong: How should income-tested benefits deal with changes in circumstances?: Winner-2019 Best Paper Prize of the Foundation for International Studies on Social security (FISS) sponsored by the Journal of Poverty and Social Justice. Journal of Poverty and Social Justice., 28(1), 3-20.

Ministry of Internal Affairs. (2019). Participatiewet [Internet]. Retrieved December 13, 2019 from https://wetten.overheid. nl/BWBR0015703/2019-07-01\#Hoofdstuk2_Paragraaf2.2_Artikel12

Moffit, R. (1983). An economic model of welfare stigma. The American Economic Review., 73(5), 1023-1035.

Moffit, R. (1992). Incentive effects of the US welfare system: A review. Journal of Economic Literature., 30(1), 1-61.

Monforte, J., \& Úbeda-Colomer, J. (2021 Dec). Tinkering with the two-to-one interview: Reflections on the use of two interviewers in qualitative constructionist inquiry. Methods in Psychology., 1(5), 100082.

Mood, C. (2004). Social influence effects on social assistance recipiency. Acta Sociologica., 47(3), 235-251.

Moynihan, D. P., Herd, P., \& Harvey, H. (2015 Jan 1). Administrative burden: Learning, psychological, and compliance costs in citizen-state interactions. Journal of Public Administration Research and Theory., 25(1), 43-69.

Moynihan, D. P., Herd, P., \& Ribgy, E. (2016 May). Policymaking by other means: Do states use administrative barriers to limit access to medicaid? Administration \& Society., 48(4), 497-524.

Mullainathan, S., \& Shafir, E. (2013). Scarcity: Why having too little means so much. Times Books, Macmillan and Henry Holt.

Netemeyer, R. G., Warmath, D., Fernandes, D., \& Lynch, J. G., Jr. (2017 Nov 7). How am I doing? Perceived financial wellbeing, its potential antecedents, and its relation to overall well-being. Journal of Consumer Research., 45(1), 68-89.

Odum, H. W. (1923). Newer ideals of public welfare. The ANNALS of the American Academy of Political and Social Science., 105(1), 1-6.

OECD. (2019). OECD employment outlook 2019: The future of work [Internet]. Retrieved from https://www.oecd-ilibrary. org/sites/9ee00155-en/index.html?itemld=/content/publication/9ee00155-en

Oliver, D. G., Serovich, J. M., \& Mason, T. L. (2005). Constraints and opportunities with interview transcription: Towards reflection in qualitative research. Social Forces, 84(2), 1273-1289.

Plano Clark, V. L., \& Ivankova, N. V. (2016). Mixed methods research: A guide to the field. SAGE Publications, Inc http:// methods.sagepub.com/book/mixed-methods-research-a-guide-to-the-field

Plano Clark, V. L., \& Ivankova, N. V. (2017). Why use mixed methods research? Identifying rationales for mixing methods. Retrieved November 9, 2019 from http://methods.sagepub.com.ezproxy.leidenuniv.nl:2048/book/mixed-methodsresearch-a-guide-to-the-field/i961.xml

Plueger, D. (2009). Earned income tax credit participation rate for tax year 2005. IRS Research Bulletin, 45, 151-195.

Reeskens, T., \& van der Meer, T. (2019 May 1). The inevitable deservingness gap: A study into the insurmountable immigrant penalty in perceived welfare deservingness. Journal of European Social Policy., 29(2), 166-181.

Rege, M., Telle, K., \& Votruba, M. (2012). Social interaction effects in disability pension participation: Evidence from plant downsizing. The Scandinavian Journal of Economics., 114(4), 1208-1239.

Ridley, M. W., Rao, G., Schilbach, F., \& Patel, V. H. (2020). Poverty, depression, and anxiety: Causal evidence and mechanisms. National Bureau of Economic Research. [Working Paper 27157].

Rinta-Kahila, T., Someh, I., Gillespie, N., Indulska, M., \& Gregor, S. (2022). Algorithmic decision-making and system destructiveness: A case of automatic debt recovery. European Journal of Information Systems., 31(3), 313-338.

Scharp, K. M. (2021). Thematic co-occurrence analysis: Advancing a theory and qualitative method to illuminate ambivalent experiences. Journal of Communication., 71(4), 545-571.

Sen, A. (1983). Poor, relatively speaking. Oxford Economic Papers., 35(2), 153-169.

Underlid, K. (2007). Poverty and experiences of insecurity. A qualitative interview study of 25 long-standing recipients of social security. International Journal of Social Welfare., 16(1), 65-74.

Van Dijk, W., Van Dillen, L. F., \& Van der Werf, M. (2022). The Psychological Inventory of Financial Scarcity (PIFS): A psychometric evaluation (Under review)

Van Manen, M. (2014). Phenomenology of practice: Meaning-giving methods in phenomenological research and writing. Left Coast Press.

Van Oorschot, W. (2006). Making the difference in social Europe: Deservingness perceptions among citizens of European welfare states. Journal of European Social Policy., 16(1), 23-42.

Van Oorschot, W. J. H. (1991 Feb). Non-take-up of social security benefits in Europe. Journal of European Social Policy., 1(1), 15-30.

Van Oorschot, W. J. H. (1994). Take it or leave it. A study of non-takeup of social security benefits. Tilburg University Press.

Vrooman, J. C., \& Asselberghs, K. T. M. (1994). Missed protection: Non-take-up of social security by financially insecure households [De gemiste bescherming; niet-gebruik van sociale zekerheid door bestaansonzekere huishoudens]. Ministery of Social Affairs and Employment.

Walker, R., Kyomuhendo, G. B., Chase, E., Choudhry, S., Gubrium, E. K., Nicola, J. Y., Lødemel, I., Mathew, L., Mwiine, A., Pellissery, S., \& Ming, Y. (2013). Poverty in global perspective: Is shame a common denominator? Journal of Social Policy., 42(2), 215-233. 
Whiteford, P. (2021). Debt by design: The anatomy of a social policy fiasco-Or was it something worse? Australian Journal of Public Administration., 80(2), 340-360.

Willig, C. (2013). Introducing qualitative research in psychology. McGraw-Hill Education.

\section{SUPPORTING INFORMATION}

Additional supporting information can be found online in the Supporting Information section at the end of this article.

How to cite this article: Simonse, O., Vanderveen, G., van Dillen, L. F., van Dijk, W. W., \& van Dijk, E. (2022). Social security or insecurity? The experience of welfare participation by financially vulnerable households in the Netherlands. Social Policy \& Administration, 1-17. https://doi.org/10.1111/spol.12849 